\title{
Deoxyribonucleic Acid Reassociation Among Members of the Genus Vibrio
}

\author{
T. E. STALEY and R. R. COLWELL \\ Department of Microbiology, University of Maryland, College Park, Maryland 20742
}

\begin{abstract}
Although application of deoxyribonucleic acid (DNA) reassociation techniques to the classification of vibrios has only recently been employed and, hence, complete data are unavailable, several generalizations regarding the results of such studies can be made. (i) Vibrio cholerae, $V$. anguillarum, and $V$. parahaemolyticus show intraspecies polynucleotide sequence variation from 80 to $100 \%$ and interspecies relatedness of approximately 20 to $30 \%$. V. parahaemolyticus shows similar intraspecies variation and interspecies relatedness with $V$. cholerae and $V$. anguillarum, but considerably higher (60 to 70\%) levels of relatedness to $V$. alginolyticus. It is not possible, at the present time, to place great reliance on other strain or species relatedness for the vibrios. (ii) Very little or no polynucleotide sequence relationship has been demonstrated between members of the genus Vibrio and the genera Pseudomonas, Aeromonas, Zymomonas, Cytophaga, and Escherichia. (iii) Based on the results of the majority of the reciprocal reactions presented, there appears to be no significant influence of genome size on DNA reassociation determinations within the genus Vibrio. Nonpathogenic marine vibrios constitute a particularly heterogeneous group with, as yet, no well-defined species.
\end{abstract}

The classification of gram-negative, rodshaped bacteria is often accomplished by employing a determinative scheme such as that proposed by Shewan et al. (24). Accordingly, motile (by means of a polar flagellum), Kovac's oxidase-positive, fermentative (acid, without gas, produced from carbohydrates in Hugh and Leifson medium), pteridine (0/129)-sensitive organisms are placed in the genus Vibrio. This classical, or "alpha" taxonomic approach has, however, come under substantial reevaluation with the advent of numerical taxonomy and molecular genetic analysis. Numerical taxonomy procedures have, in general, provided results in good agreement with alpha taxonomy, and the correlation of molecular genetic analyses with alpha taxonomy often is also reasonably good. To date, speciation within the genus Vibrio has not been attempted on a completely quantitative basis and, as such, no widely accepted taxonomy for the genus has been proposed. It was not until the late 1960's that numerical taxonomy studies of members of this genus, in particular, $V$. cholerae, $V$. parahaemolyticus, and certain marine isolates, were begun. Furthermore, since that time only a few papers have appeared in the literature concerning the deoxyribonucleic acid (DNA) reassociation relationships among members of the genus Vibrio. To date, Hanaoka et al. (15), Anderson and Ordal (1), Basden et al. (2), Kiehn and Pacha (18), Citarella and Colwell (9), and Staley and Colwell (27) have published molecular data for this genus. It is the intent of this paper to review the available literature concerning DNA relationships among strains of bacteria classified as members of the genus Vibrio. In addition, we will attempt an assessment of the validity of type and neotype strains as representative of a given species, the extent of inter- and intrageneric DNA relationships, the usefulness of mol percent guanine plus cytosine determination as a measure of molecular genetic relatedness, and a comparison of the Vibrio genospecies with the taxospecies.

(This paper was presented at the 73rd Annual Meeting of the American Society of Microbiology, 7 May 1973, Miami, Florida.)

DNA reassociation technique. The current popularity of the DNA reassociation technique (also called DNA homology, hybridization, or molecular genetic analysis) is best documented by citing the large number of papers in the literature. The reports can be divided into two general catagories: (i) those designed to differentiate selected reference strains from a relatively few isolates, and (ii) those designed to delineate the range of taxonomic groups. Both 
types of studies are subject to potential intrinsic errors of the technique (incomplete pairing of base sequences, differences in genome size between reference and test strains, extrachromosomal DNA elements, variations in reassociation rates as a function of base composition, enriched sequences due to replication state,or low-level redundancy), all of which have been discussed elsewhere $(7,8,23,27)$. In spite of these limitations, both the differentiation and taxonomic range types of study have corroborated or complemented results of the alpha taxonomies. In some cases, unexpected, subtle differences not detectable by any other procedure have been revealed $(7,9,27)$.

The technology applicable to the separation of single- from double-stranded DNA duplexes, the crucial step upon which all DNA reassociation calculations depend, has been amply discussed in the literature $(5,6,13 ; T$. E. Staley and R. R. Colwell, Annu. Rev. Ecol. Syst., in press). The most important single consideration in using this technique as a taxonomic tool is the choice of reference strains against which all other strains are compared. Two lines of research are possible. One involves the use of type strains, designated by the individual describing a given taxon. The type strain may be the first isolate or may have special characteristics, as decided by the individual preparing the description of the taxon in question. The other line of research makes use of the hypothetical median organism (19), computed by numerical taxonomy and used to select the reference organism or type strain. Numerical taxonomy has not yet, unfortunately, been used extensively to select type strains. It would appear more logical to develop a classification by selection of strains representing those closely related to a median organism. Sets of strains can be subjected to numerical taxonomy analysis and the median organism calculated can be used as the reference strain for DNA reassociation determinations. In the few cases where other than a random selection of a reference strain was made $(9,10,21)$, the correlation of percent DNA reassociation and percent similarity values were high. Unfortunately, Palleroni et al. (21) reported the selection of reference strains of Pseudomonas stutzeri and Pseudomonas putida, based on numerical analysis of phenetic characters, that were genetically atypical of both species. Nevertheless, the use of a hypothetical median organism for the selection of reference strains intuititively would seem the "best choice" for molecular taxonomy studies. No reports have yet appeared in the literature specifically addressing themselves to this problem, although such studies would be a prerequisite for the development of a stable and reproducible microbial taxonomy.

As an additional precautionary note in interpreting DNA reassociation data, it should be kept in mind that, unless two reference strains have been shown to be $>50 \%$ related to each other, any inference of nucleotide sequence relationship between these strains, derived from their relationship with a common test strain, may be purely conjectural.

Vibrio strains examined. In Table 1 are listed all the Vibrio strains examined by DNA reassociation techniques to date. It is evident that a major effort has been given to identification and classification of isolates pathogenic for humans ( $V$. cholerae and $V$. parahaemolyticus) and fish ( $V$. anguillarum). Unfortunately, very little interest has been shown in DNA sequence relationships of nonpathogenic vibrios. It is obvious that this situation must be remedied before a reliable and reproducible classification of vibrios can be accomplished.

All strains cited in Table 1 were assumed to be individual isolates. Any strain indicated by an investigator (or found by the authors) to be identical to any other strain is so noted in the last two columns of the table. Although we are not absolutely certain, it appears that $V$. parahaemolyticus strain 4 (strains SAK 4 and, probably, $\mathrm{K} 4$ also) is identical to the $\mathrm{K} 4$ pilot strains of Anderson and Ordal (1) and Hanaoka et al. (15), which are based on common $O$ and $\mathrm{K}$ antigenic components. Similarly, $V$. parahaemolyticus strains 15 and A55, 23 and $\mathrm{K}-23$ pilot, 5 and $\mathrm{K}-5$ pilot, 1 and $\mathrm{K}-1$ pilot, 17 and K-17 pilot appear to be identical strain pairs. Seven of the ten pilot strains used by Hanaoka et al. (15) were assumed to be identical to strains similarly designated by Anderson and Ordal (1).

Intrageneric DNA relationships. To assess quantitatively the molecular genetic relationships among members of the genus Vibrio, the available DNA reassociation data were analyzed using a single-linkage clustering method similar to that used in numerical taxonomy. The triangular matrix obtained is shown in Fig. 1. Although the paucity of data available precludes a precise interpretation of the matrix, some generalizations concerning group relationships are, nonetheless, possible. We have constructed Table 2 to illustrate certain of these relationships.

$V$. cholerae shows intraspecies variation of approximately 80 to $100 \%$, as does $V$. anguillarum, $V$. parahaemolyticus, and $V$. alginolyticus. $V$. cholerae shows only 20 to $38 \%$ relatedness to the other groups. No data were 


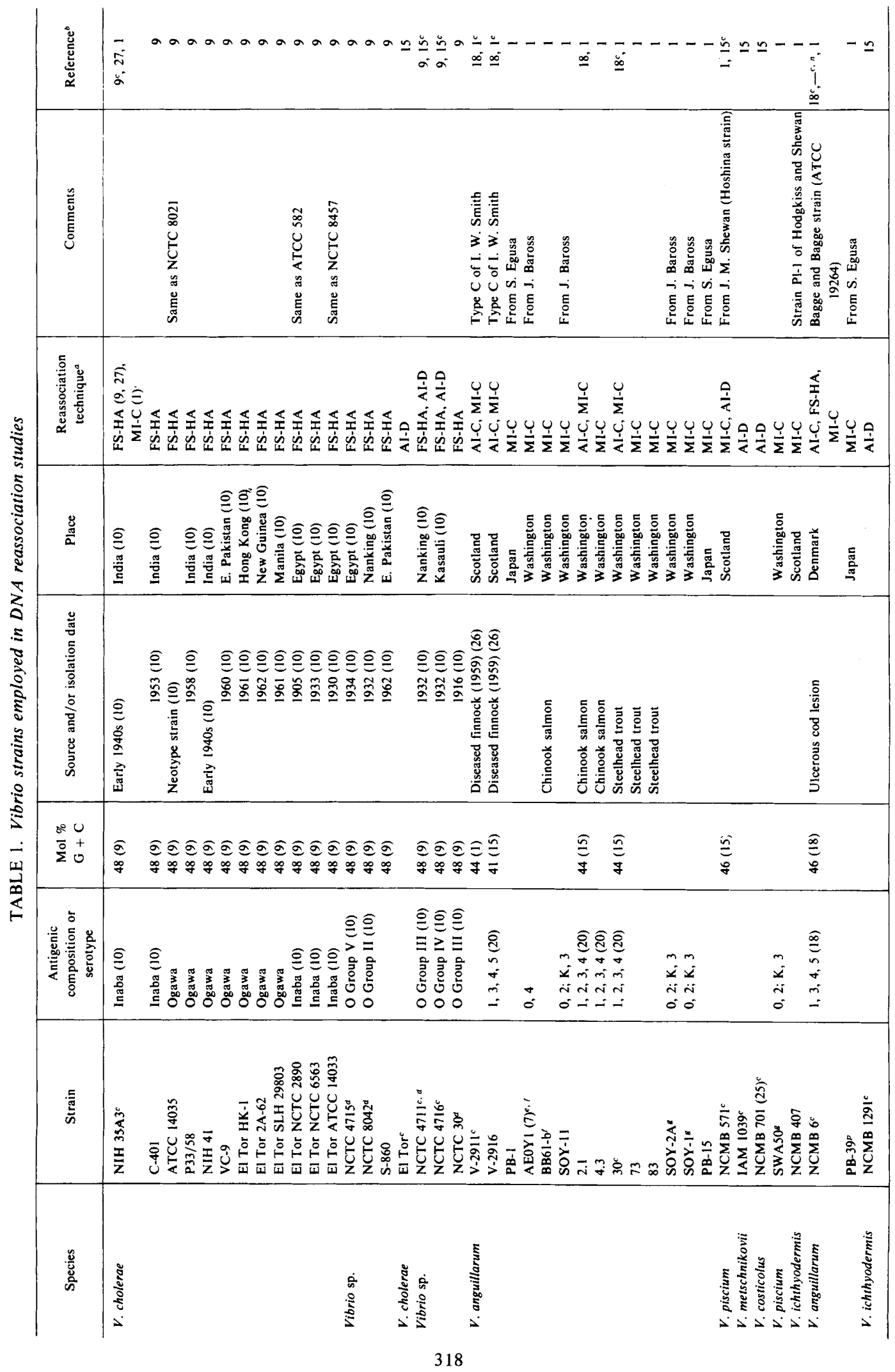




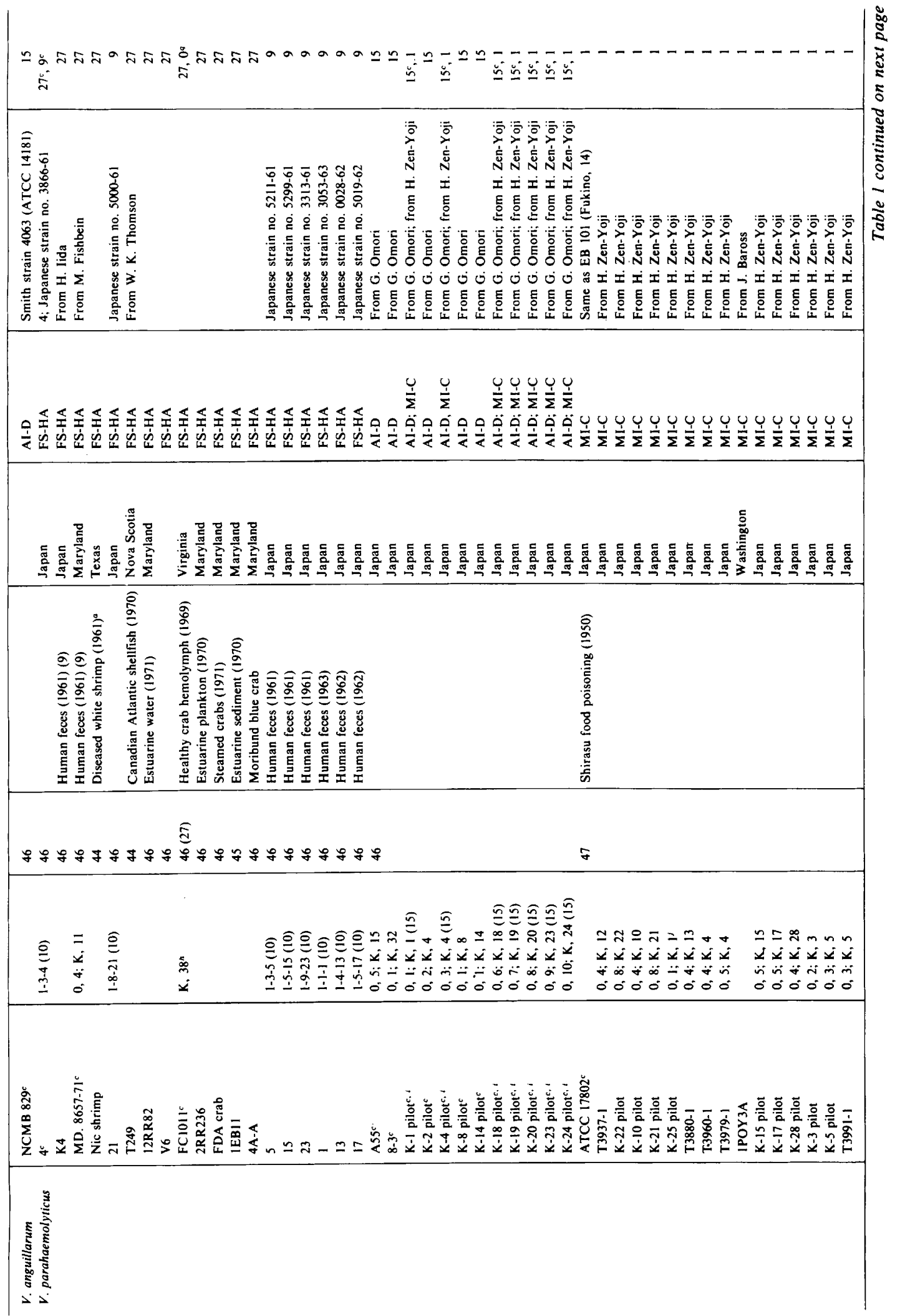




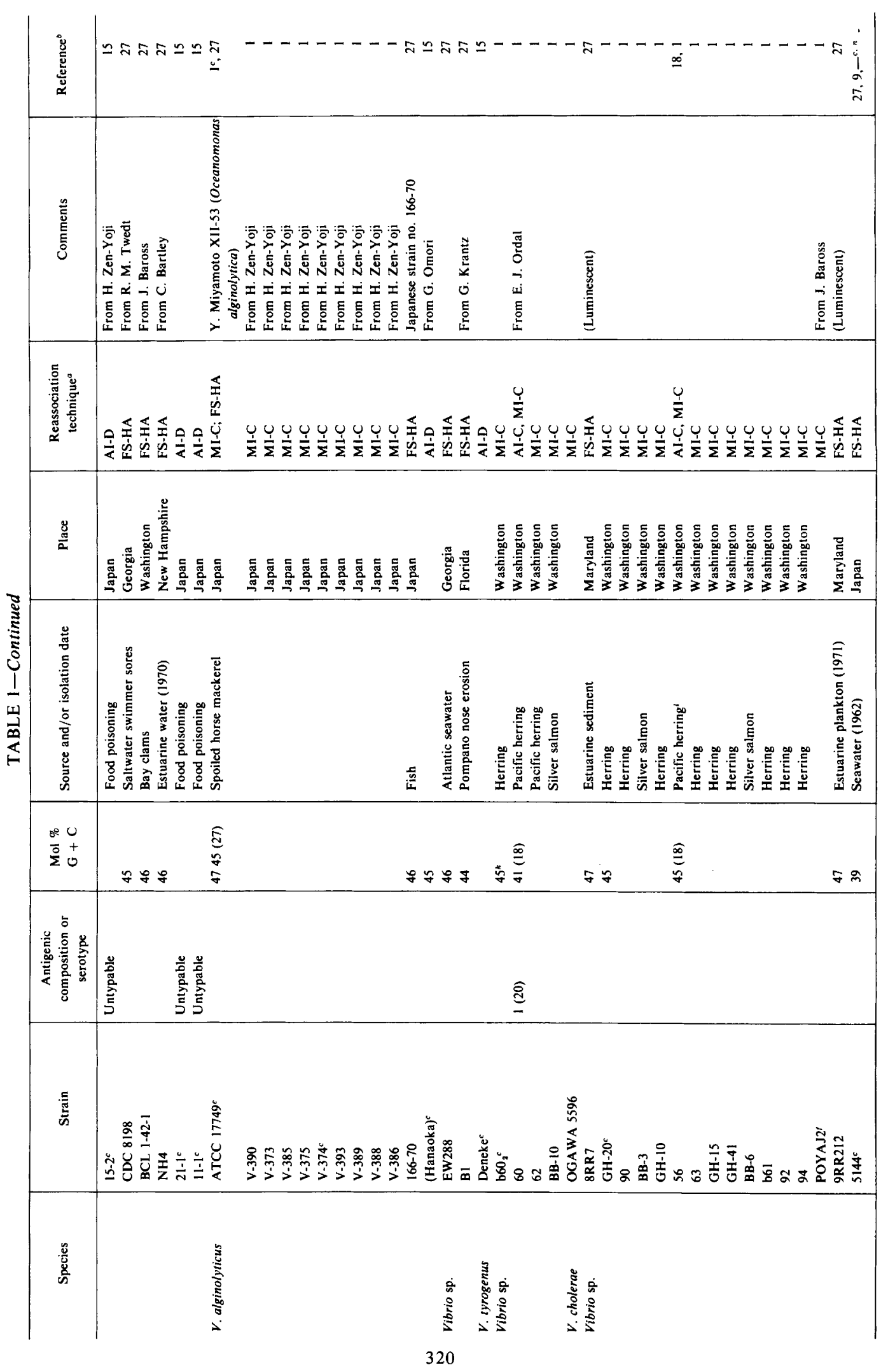




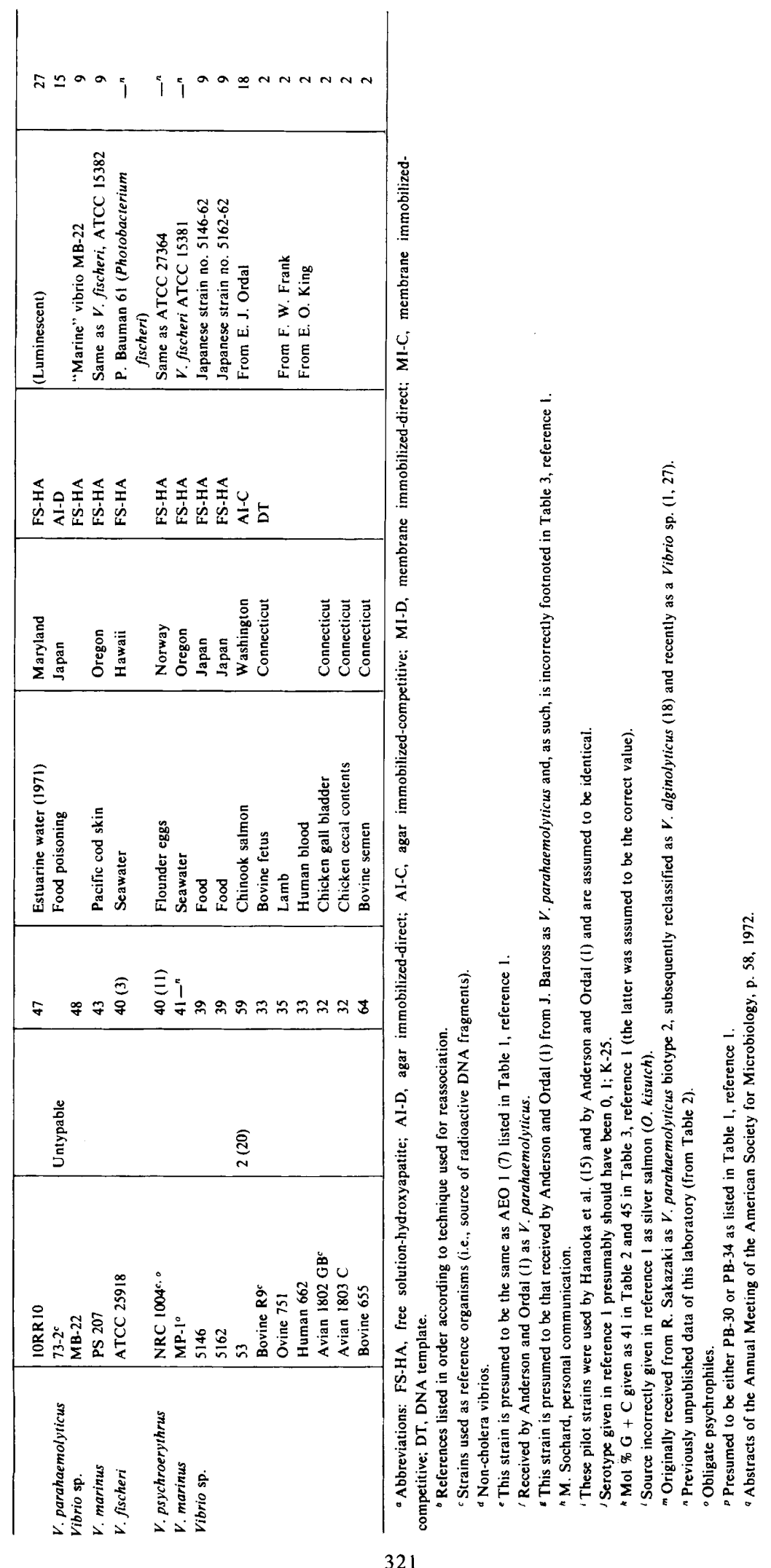




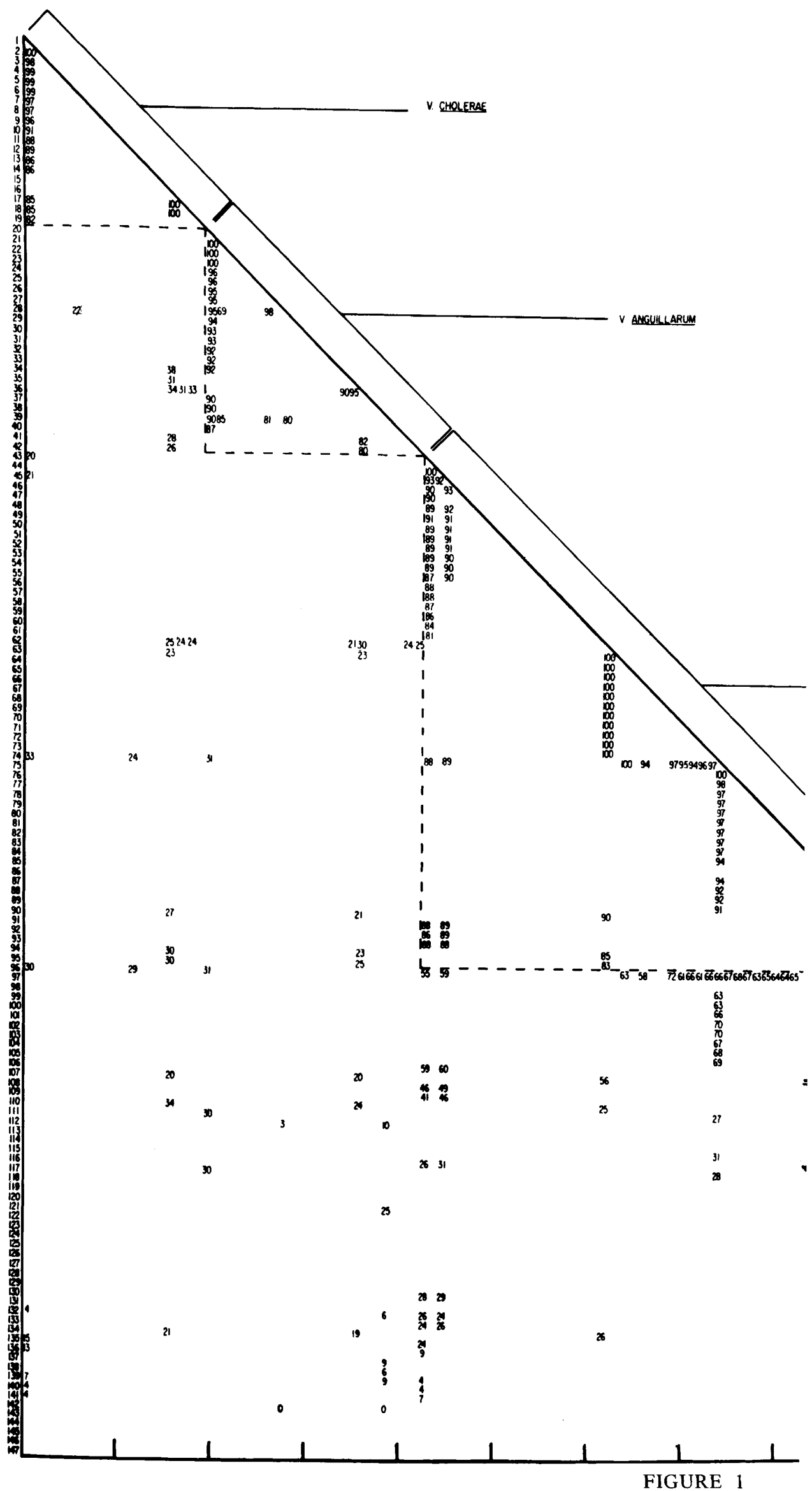




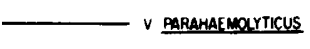

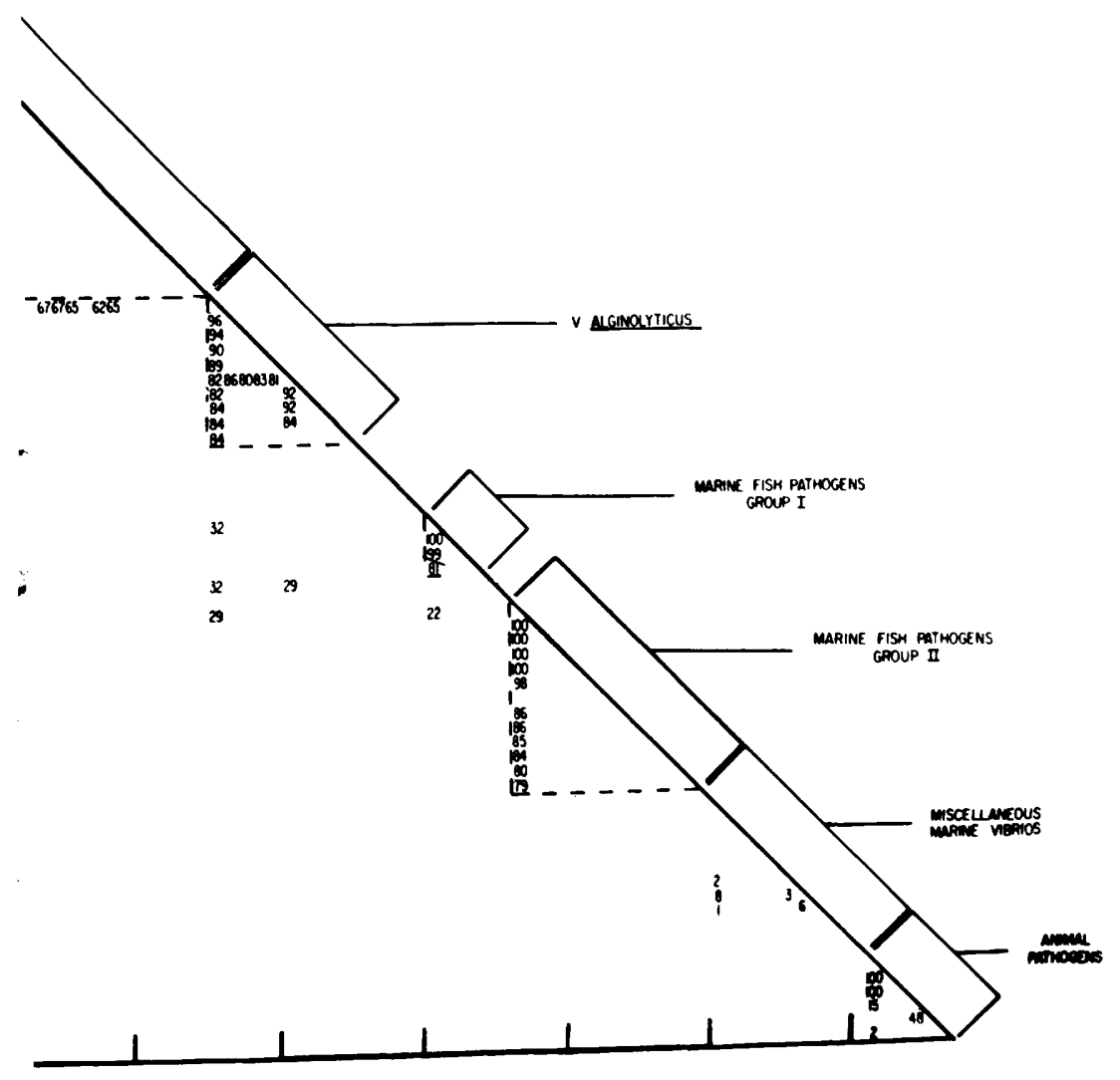


FIG. 1. Intrageneric polynucleotide sequence relationships expressed as a total triangular DNA reassociation matrix. Asterisk indicates the strain used as the reference. In the case of reciprocal reactions, only one of the two values was used (consult Table 3 for reciprocal reaction values).

\begin{tabular}{|c|c|c|c|c|c|}
\hline $\begin{array}{c}\text { Code } \\
\text { no. }\end{array}$ & Nomenspecies & Strain & $\begin{array}{c}\text { Code } \\
\text { no. }\end{array}$ & Nomenspecies & Strain \\
\hline 1. & $V$. cholerae & NIH 35A3 & 57. & V. parahaemolyticus & 15 \\
\hline 2. & $V$. cholerae & C-401 & 58. & $V$. parahaemolyticus & 23 \\
\hline 3. & V. cholerae & ATCC 14035 & 59. & V. parahaemolyticus & 1 \\
\hline 4. & $V$. cholerae & P33/58 & 60. & V. parahaemolyticus & 13 \\
\hline 5. & $V$. cholerae & NIH 41 & 61. & V. parahaemolyticus & 17 \\
\hline 6. & $V$. cholerae & VC-9 & 62. & V. parahaemolyticus & $*$ A55 \\
\hline 7. & V. cholerae & El Tor HK-1 & 63. & $V$. parahaemolyticus & $* 8-3$ \\
\hline 8. & $V$. cholerae & El Tor $2 A-62$ & 64. & V. parahaemolyticus & ${ }^{*} \mathrm{~K}-1$ pilot \\
\hline 9. & $V$. cholerae & El Tor SLH 29803 & 65. & V. parahaemolyticus & ${ }^{*} \mathrm{~K}-2$ pilot \\
\hline 10. & V. cholerae & El Tor NCTC 2890 & 66. & V. parahaemolyticus & ${ }^{*} \mathrm{~K}-4$ pilot \\
\hline 11. & V. cholerae & El Tor NCTC 6563 & 67. & V. parahaemolyticus & ${ }^{*} \mathrm{~K}-8$ pilot \\
\hline 12. & $V$. cholerae & El Tor ATCC 14033 & 68. & V. parahaemolyticus & ${ }^{*} \mathrm{~K}-14$ pilot \\
\hline 13. & Vibrio sp. & NCTC 4715 & 69. & V. parahaemolyticus & ${ }^{*} \mathrm{~K}-18$ pilot \\
\hline 14. & Vibrio sp. & NCTC 8042 & 70. & $V$, parahaemolyticus & ${ }^{*} \mathrm{~K}-19$ pilot \\
\hline 15. & Vibrio sp. & S-860 & 71. & V. parahaemolyticus & ${ }^{*} \mathrm{~K}-20$ pilot \\
\hline 16. & $V$. cholerae & *El Tor & 72. & V. parahaemolyticus & ${ }^{*} \mathrm{~K}-23$ pilot \\
\hline 17. & Vibrio sp. & *NCTC 4711 & 73. & V. parahaemolyticus & ${ }^{*} \mathrm{~K}-24$ pilot \\
\hline 18. & Vibrio sp. & ${ }^{*}$ NCTC 4716 & 74. & V. parahaemolyticus & ${ }^{*}$ ATCC 17802 \\
\hline 19. & Vibrio sp. & NCTC 30 & 75. & V. parahaemolyticus & T3937-1 \\
\hline 20. & V. anguillarum & $* V-2911$ & 76. & V. parahaemolyticus & $\mathrm{K}-22$ pilot \\
\hline 21. & V. anguillarum & V-2916 & 77. & V. parahaemolyticus & $\mathrm{K}-10$ pilot \\
\hline 22. & V. anguillarum & PB-1 & 78. & V. parahaemolyticus & $\mathrm{K}-21$ pilot \\
\hline 23. & $V$. anguillarum & AEOY1 (7) & 79. & $V$. parahaemolyticus & K-25 pilot \\
\hline 24. & $V$. anguillarum & BB61-b & 80. & V. parahaemolyticus & T3880-1 \\
\hline 25. & $V$. anguillarum & SOY -11 & 81. & V. parahaemolyticus & T3960-1 \\
\hline 26. & $V$. anguillarum & 2.1 & 82. & V. parahaemolyticus & T3979-1 \\
\hline 27. & $V$. anguillarum & 4.3 & 83. & V. parahaemolyticus & 1POY3A \\
\hline 28. & V. anguillarum & $* 30$ & 84. & V. parahaemolyticus & K-15 pilot \\
\hline 29. & $V$. anguillarum & 73 & 85. & V. parahaemolyticus & K-17 pilot \\
\hline 30. & $V$. anguillarum & 83 & 86. & V. parahaemolyticus & $\mathrm{K}-28$ pilot \\
\hline 31. & $V$. anguillarum & SOY $-2 A$ & 87. & $V$. parahaemolyticus & K-3 pilot \\
\hline 32. & V. anguillarum & SOY -1 & 88. & V. parahaemolyticus & K-5 pilot \\
\hline 33. & V. anguillarum & PB-15 & 89. & $V$. parahaemolyticus & T3991-1 \\
\hline 34. & $V$. piscium & *NCMB 571 & 90. & V. parahaemolyticus & $* 15-1$ \\
\hline 35. & V. metschnikovii & *IAM 1039 & 91. & V. parahaemolyticus & CDC 8198 \\
\hline 36. & V. costicolus & *NCMB 701 & 92. & V. parahaemolyticus & BCL $1-42-1$ \\
\hline 37. & $V$. piscium & SWA 50 & 93. & V. parahaemolyticus & $\mathrm{NH} 4$ \\
\hline 38. & V. ichthyodermis & NCMB 407 & 94. & V. parahaemolyticus & $* 21-1$ \\
\hline 39. & V. anguillarum & *NCMB 6 & 95. & $V$. parahaemolyticus & $* 11-1$ \\
\hline 40. & $V$. anguillarum & PB-39 & 96. & $V$. alginolyticus & *ATCC 17749 \\
\hline 41. & $V$. ichthyodermis & *NCMB 1291 & 97. & V. alginolyticus & V-390 \\
\hline 42. & $V$. anguillarum & *NCMB 829 & 98. & V. alginolyticus & V-373 \\
\hline 43. & V. parahaemolyticus & $* 4$ & 99. & $V$. alginolyticus & $V-385$ \\
\hline 44. & V. parahaemolyticus & K4 & 100. & $V$. alginolyticus & V-375 \\
\hline 45. & V. parahaemolyticus & *MD 8657-71 & 101. & $V$. alginolyticus & $V-374$ \\
\hline 46. & V. parahaemolyticus & Nic shrimp & 102. & $V$. alginolyticus & V-393 \\
\hline 47. & V. parahaemolyticus & 21 & 103. & $V$. alginolyticus & $V-389$ \\
\hline 48. & V. parahaemolyticus & T249 & 104. & $V$. alginolyticus & V-388 \\
\hline 49. & V. parahaemolyticus & 12RR82 & 105. & V. alginolyticus & V-386 \\
\hline 50. & $V$. parahaemolyticus & V6 & 106. & V. alginolyticus & $166-70$ \\
\hline 51. & $V$ parahaemolyticus & *FC1011 & 107. & $V$. alginolyticus & *(Hanaoka) \\
\hline 52. & V. parahaemolyticus & 2RR236 & 108. & Vibrio sp. & EW288 \\
\hline 53. & $V$. parahaemolyticus & FDA crab & 109. & Vibrio sp. & B1 \\
\hline 54. & V. parahaemolyticus & $1 \mathrm{~EB} 11$ & 110. & $V$. tyrogenes & *Deneke \\
\hline 55. & V. parahaemolyticus & $4 \mathrm{~A}-\mathrm{A}$ & 111. & Vibrio sp. & ${ }^{*} \mathrm{~b} 60_{2}$ \\
\hline 56. & V. parahaemolyticus & 5 & 112. & Vibrio sp. & 60 \\
\hline
\end{tabular}


FIGURE 1 legend-Continued

List of strains used in the total triangular DNA reassociation matrix in Fig. $I$

\begin{tabular}{|c|c|c|c|c|c|}
\hline $\begin{array}{c}\text { Code } \\
\text { no. }\end{array}$ & Nomenspecies & Strain & $\begin{array}{c}\text { Code } \\
\text { no. }\end{array}$ & Nomenspecies & Strain \\
\hline $\begin{array}{l}113 . \\
114 . \\
115 . \\
116 . \\
117 . \\
118 . \\
119 . \\
120 . \\
121 . \\
122 . \\
123 . \\
124 . \\
125 . \\
126 . \\
127 . \\
128 . \\
129 . \\
130 .\end{array}$ & $\begin{array}{l}\text { Vibrio sp. } \\
\text { Vibrio sp. } \\
\text { V. cholerae } \\
\text { Vibrio sp. } \\
\text { Vibrio sp. } \\
\text { Vibrio sp. } \\
\text { Vibro sp. } \\
\text { Vibro sp. } \\
\text { Vibro } \mathrm{sp} . \\
\text { Vibrio sp. } \\
\text { Vibrio sp. } \\
\text { Vibrio sp. } \\
\text { Vibrio sp. } \\
\text { Vibrio sp. } \\
\text { Vibrio sp. } \\
\text { Vibrio sp. } \\
\text { Vibrio sp. } \\
\text { Vibrio } \mathrm{sp} .\end{array}$ & $\begin{array}{l}62 \\
\text { BB-10 } \\
\text { OGAWA } 5596 \\
8 \text { RR7 } \\
*^{*} \text { GH-20 } \\
90 \\
\text { BB-3 } \\
\text { GH-10 } \\
56 \\
63 \\
\text { GH-15 } \\
\text { GH-41 } \\
\text { BB-6 } \\
\text { b61 } \\
\text { 92 } \\
\text { 94 } \\
\text { POYAJ } 2 \\
\text { 9RR212 }\end{array}$ & $\begin{array}{l}131 . \\
132 . \\
133 . \\
134 . \\
135 . \\
136 . \\
137 . \\
138 . \\
139 . \\
140 . \\
141 . \\
142 . \\
143 . \\
144 . \\
145 . \\
146 . \\
147 .\end{array}$ & $\begin{array}{l}\text { Vibrio sp. } \\
\text { Vibrio sp. } \\
\text { V. parahaemolyticus } \\
\text { Vibrio sp. } \\
\text { V. marinus } \\
\text { V. fisherii } \\
\text { V. psychroerythrus } \\
\text { V. marinus } \\
\text { Vibrio sp. } \\
\text { Vibrio sp. } \\
\text { Vibrio sp. } \\
\text { Vibrio sp. } \\
\text { Vibrio sp. } \\
\text { Vibrio sp. } \\
\text { Vibrio sp. } \\
\text { Vibrio sp. } \\
\text { Vibrio sp. }\end{array}$ & $\begin{array}{l}\text { *5144 } \\
10 \mathrm{RR} 10 \\
* 73-2 \\
\text { MB-22 } \\
\text { PS } 207 \\
\text { *ATCC } 25918 \\
\text { NRC } 1004 \\
\text { MP-1 } \\
5146 \\
5162 \\
53 \\
\text { *bovine R9 } \\
\text { ovine } 751 \\
\text { human } 662 \\
\text { *avian } 1802 \mathrm{~GB} \\
\text { avian } 1803 \mathrm{C} \\
\text { bovine } 655\end{array}$ \\
\hline
\end{tabular}

available on relationships of $V$. cholerae with the marine fish pathogens.

$V$. anguillarum was found to be 20 to $38 \%$ related to $V$. cholerae, $V$. parahaemolyticus, and $V$. alginolyticus. Based on a rather limited number of observations, $V$. anguillarum appears to be only 25 to $30 \%$ related to the marine fish pathogens studied by Anderson and Ordal (the strain designations $\mathrm{GH}-20$ and $\mathrm{b}^{6} \mathrm{O}_{2}$ are synonymous with the group designations II and I, respectively, in Fig. 1). The proposal by Hendrie et al. (16) that $V$. anguillarum includes $V$. piscium and $V$. ichthyodermis strains is supported by the results shown in Fig. 1.

$V$. parahaemolyticus appears to be related to $V$. cholerae and $V$. anguillarum at about 20 to $30 \%$ and $V$. alginolyticus at 58 to $70 \%$. Based on only two determinations, the fish pathogens (I and II) were 27 to $28 \%$ related to $V$. parahaemolyticus.

$V$. alginolyticus (most likely including strains 166-70 and "Hanaoka" based on their relationships with the other species) was, in addition to the relationships already cited, only 29 to $32 \%$ related to the two marine fish pathogens.

The extreme molecular genetic heterogeneity noted among the miscellaneous marine vibrios can be seen in Fig. 1 and Table 3. We suggest that these strains (including Vibrio sp. EW288 and $\mathrm{B} 1, V$. tyrogenus strain Deneke, and Vibrio sp. 8RR7) be examined further before being designated or accepted as species within the genus Vibrio.
The single-linkage analysis procedure separated $V$. cholerae strain Ogawa 5596 from $V$. cholerae. However, based on the relationship of this strain with $V$. alginolyticus (29 and 32\%) and $V$. parahaemolyticus $(31 \%)$, it should be included in $V$. cholerae.

The animal pathogens appeared to be heterogenous; however, relationships of these strains with strains of the other groups were not examined.

Extrapolating from the work of Brenner et. al. (7), who studied well-characterized strains of the genera Escherichia and Salmonella and found them to be 40 to $50 \%$ related to each other on the basis of nucleotide homologies, it seems likely that the genus Vibrio may, as presently defined, encompass more than one genus if uniform levels of molecular genetic relatedness are to be used as the index of relatedness for the genus Vibrio. Based on the data given in Table 2, two and possibly three new genera showing high species relatedness $(>80 \%)$ and no more than 25 to $35 \%$ DNA relatedness for the genus Vibrio. Thus, based on the data given in Table 2, two and possibly three new genera showing high species relatedness $(>80 \%)$ and no more than 25 to $35 \%$ DNA molecular genetic terms. Significant correlation of the numerical taxonomy and DNA reassociation data would support such a proposal. However, it must be kept in mind that interpretation of reassociation values as species or genus levels of taxonomic relatedness re- 
TABLE 2. Intrageneric polynucleotide sequence relationships (expressed as percentage of relative binding) with in the genus Vibrio

\begin{tabular}{l|l|l|l|l}
\hline \multicolumn{1}{c|}{ Organism } & V. cholerae & V. anguillarum & $\begin{array}{c}\text { V. parahae- } \\
\text { molyticus }\end{array}$ & V.alginolyticus \\
\hline V. cholerae & $82-100(18)^{a}$ & & & \\
V. anguillarum & $22-38(8)$ & $80-100(26)^{b}$ & & \\
$V$. parahaemolyticus & $20-33(19)$ & $21-31(9)$ & $81-100(70)$ & \\
V. alginolyticus & $29-33(4)$ & $31(1)$ & $58-70(34)^{c}$ & $80-96(16)$ \\
Marine fish pathogens & ND $d$ & $3^{e}-30(6)$ & $27-28(2)$ & $29-32(2)$ \\
Miscellaneous marine vibrios & $4-21(7)$ & $0-19(7)$ & $4-26(10)$ & ND \\
\hline
\end{tabular}

${ }^{a}$ Parentheses contain number of strains examined within designated range.

$b$ The values of $69 \%$ for the $V$. anguillarum strain $30 * / V$. anguillarum V-2916 and $71 \%$ for the $V$. anguillarum strain $30 * / V$. anguillarum V-2911 reactions indicated by Kiehn and Pacha (18) seem to be rather low (24 to $26 \%$ ), since Anderson and Ordal (1) have reported the reciprocal of the latter reaction to be $95 \%$. (Strains followed by asterisks indicate reference strains.)

${ }^{c}$ Assuming $V$. alginolyticus $166-70$ and "Hanaoka" are $>80 \%$ homologous to any one of the strains in the $V$. alginolyticus group.

${ }^{d}$ ND, no data available.

$\boldsymbol{e}$ Probably too low for the same reason given in footnote $b$ above.

TABLE 3. Polynucleotide sequence relationships among various marine vibrios (previously unpublished data of this laboratory)

\begin{tabular}{|c|c|c|c|c|c|c|c|}
\hline \multirow[b]{2}{*}{ Organism } & \multicolumn{2}{|c|}{$\begin{array}{c}V . \text { psychroerythrus } \\
\text { NRC } 1004^{a}\end{array}$} & \multicolumn{2}{|c|}{$\begin{array}{l}\text { Vibrio sp. } \\
5144^{a}\end{array}$} & \multicolumn{2}{|c|}{$\begin{array}{l}\text { V. anguillarum } \\
\text { NCMB6 }^{a}\end{array}$} & \multirow[b]{2}{*}{$\mathrm{Mol} \% \mathrm{G}+\mathrm{C}^{c, d}$} \\
\hline & $\begin{array}{c}\% \text { Relative } \\
\text { binding, } \\
60 \mathrm{C}^{b, d}\end{array}$ & $\mathrm{~T}_{\mathrm{m}}^{\Delta}(\mathrm{e})^{d}$ & $\begin{array}{c}\% \text { Relative } \\
\text { binding, } \\
60 C^{b, d}\end{array}$ & $\stackrel{\Delta}{\mathrm{T}_{\mathrm{m}}(\mathrm{e})^{d}}$ & $\begin{array}{l}\% \text { Relative } \\
\text { binding, } \\
60 \mathrm{C}^{b, d}\end{array}$ & $\mathrm{~T}_{\mathrm{m}}(\mathrm{e})^{d}$ & \\
\hline $\begin{array}{l}\text { V. psychroerythrus } \\
\text { NRC1004 }\end{array}$ & 100 & & 1 & 8.5 & 6 & 8.0 & 40 \\
\hline Vibrio sp. 5144 & 8 & 5.0 & 100 & & $6^{*}$ & $9.0^{*}$ & 39 \\
\hline$V$. anguillarum NCMB 6 & 5 & 3.5 & 2 & 6.5 & 100 & & 45 \\
\hline$V$. marinus MP-1 & 6 & $5.5 *$ & 1 & 7.5 & $9^{*}$ & $8.0^{*}$ & 41 \\
\hline V. fischeri ATCC 25918 & 3 & 4.5 & 2 & 7.0 & 9 & 10.0 & 40 \\
\hline
\end{tabular}

${ }^{a}$ Source of ${ }^{32}$ P-labeled DNA fragments.

$b$ Percentage of actual binding at $60 \mathrm{C}$ was 90,89 , and $85 \%$, respectively, for $V$. psychroerythrus NRC1004, Vibrio sp. 5144, and V. anguillarum NCMB6 homologous reactions. Self-reassociation amounted to between 5 and $10 \%$ of the homologous reaction with zero-time binding amounting to $<0.5 \%$ (calculations and procedure for determining \% relative binding described in reference 27$)$.

c Calculated from thermal mid-point determined spectrophotometrically.

$d$ Arithmetic average of triplicate determinations (asterisk indicates average of duplicate determinations).

mains equivocal and will remain so until some agreement is reached among taxonomists and molecular geneticists.

Intergeneric DNA relationships. The use of one or, in some cases, several characteristics to differentiate genera (namely the scheme of Shewan (24) for differentiating Vibrio from other gram-negative genera, such as Aeromonas, based on the sensitivity to compound $0 / 129$ ) is obviously open to serious question. Nevertheless, the few data available (Table 4) indicate that no, or very few, polynucleotide sequences are held in common between any of the Vibrio strains examined and selected strains of Aeromonas, Pseudomonas, Zymomonas, Cytophaga, or Escherichia. The corroboration of results using such schemes with molecular genetic criteria might be explained by the fact that the single characteristics selected to separate the genera represent "critical" metabolic pathways. Hence, the presence or absence of the given character sums up chains of metabolic events, thus serving to demark generic separations. The data provided in Table 4 could be interpreted as indicating low levels of relatedness (6 to 13\%) between vibrios and selected 


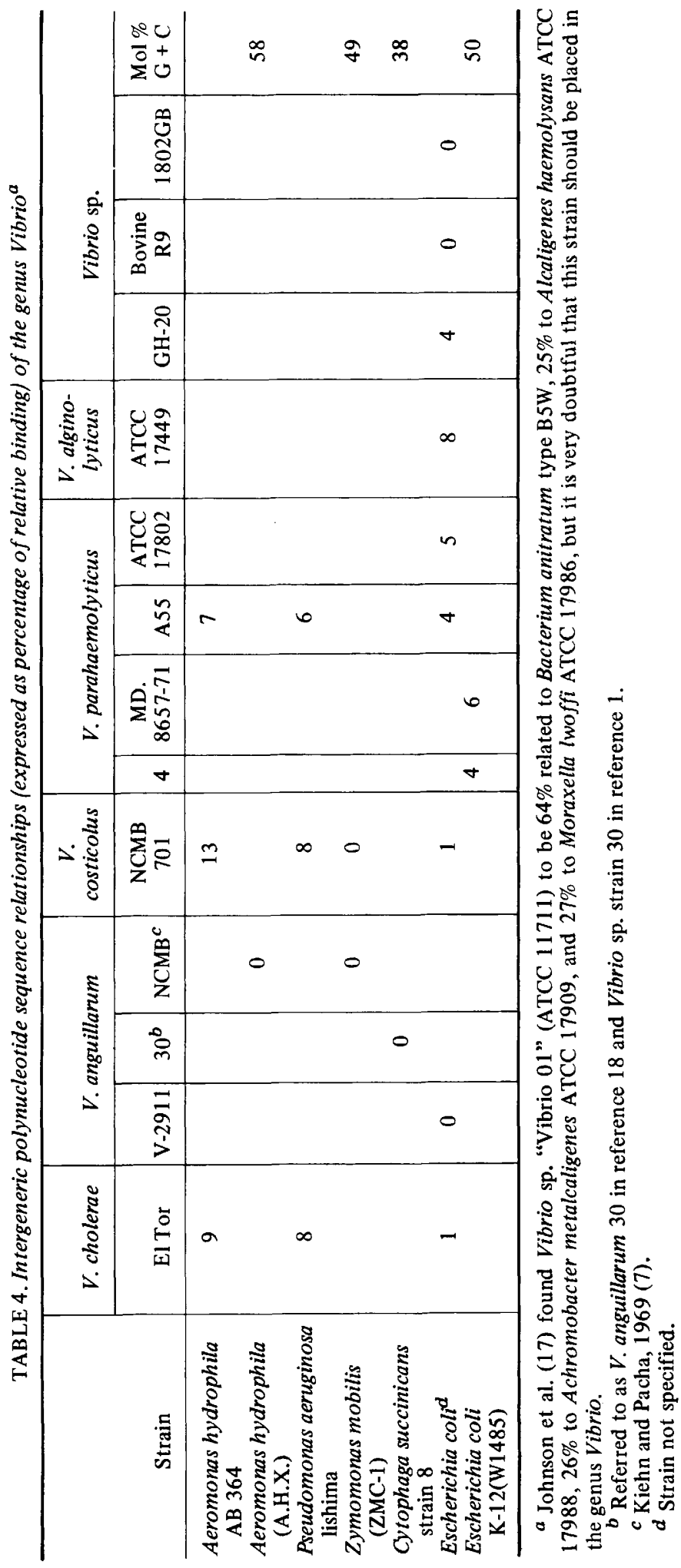


Pseudomonas and Aeromonas strains. However, until a more complete set of data is available, with many more "typical" strains included, such relationships are merely conjectural. Molecular genetic relatedness values of $<5 \%$ (as seen in Table 4 for the Zymomonas, Cytophaga, and Escherichia/Vibrio reactions) approach the limits of accuracy of the technique and, as such, may represent background "noise." In addition, the problem of assessing mispaired base sequences in heteroduplexes of DNA obtained from distantly related organisms becomes particularly acute and, in fact, has been ignored by most workers until recently.

At the moment the extent of our knowledge allows us only to say that, in the few DNA reassociation studies reported, there appears to be very little polynucleotide sequence relatedness among members of the genus Vibrio and some members of Aeromonas, Pseudomonas, Zymomonas, Cytophaga, or Escherichia.

Necessity of reciprocal DNA reactions. The molecular genetic relationship (percentage of DNA reassociation) of organism A with organism $B$ can be determined by annealing radioactive, single-stranded DNA fragments of strain $\mathrm{A}$ with nonradioactive, single-stranded DNA fragments of strain B. Similarly, the reciprocal relationship of strain $B$ to $A$ can be assessed by using radioactivity labeled $B$ in place of A. Theoretically, within the experimental error of the particular technique in question (usually \pm 1 to $5 \%$ ), the relative values of such reciprocal reactions should be identical. As shown in Table 5, 15 of 19 values for such reciprocal reactions lie within an acceptable experimental error range. Four of the values for reciprocal reactions showed differences of $7 \%$ ( $V$. psychroerythrus NRC 1004/Vibrio sp. $5144), 8 \%$ (V. parahaemolyticus A55/V. costicolus NCMB 701), 24\% (V. anguillarum 30/V. anguillarum V-2911), and $37 \%$ (V. parahaemolyticus ATCC 17802 /and V. alginolyticus $\mathrm{V}-374)$. The first two reciprocal value differences, although slightly outside of the anticipated error, might well fall within the accuracy of the given experiment. Alternatively, assuming these differences are real, an additional explanation for such results might be that the genome sizes (i.e., the total polynucleotide sequence complement of the cell, including possible episomal, temperate phage, and/or doubly replicated regions due to multiple growing points, as well as redundant sequences) of the strains used for the reciprocal reactions are substantially different.

The magnitude of the difference in genome size, generating a constant, significant recipro- cal value difference, increases as the number of polynucleotide sequences which are held in common between the two strains being compared decreases. This concept might best be illustrated by the following example. Two strains, $\mathrm{A}$ and $\mathrm{B}$, are reciprocally reacted and are found to be related as $\mathrm{A} / \mathrm{B}=90 \%$ and $\mathrm{B} / \mathrm{A}=80 \%$ (a reciprocal difference of $10 \%$ ). This situation can only arise if $\mathrm{B}>\mathrm{A}$, since $\mathrm{B}$ must contain all the homologous sequences present in A, plus $20 \%$ nonhomologous sequences. The genome size of $\mathrm{B}$ relative to $\mathrm{A}$ can then be calculated. Since $80 \%$ of the sequences in $\mathrm{B}$, held in common with $\mathrm{A}$, represent $90 \%$ of the sequences in $\mathrm{A}$, some percentage $(\chi)$ of the sequences in B must equal $100 \%$ of the sequences in $\mathrm{A}$. By simple proportions, $\chi$, in this case, is 1.12 , i.e., the genome of strain B is $12 \%$ larger than $\mathrm{A}$. Using the same rationale, the genome size difference between two strains, $\mathrm{C}$ and $\mathrm{D}$ (reciprocally related, $\mathrm{C} / \mathrm{D}=70 \%$ and $\mathrm{D} / \mathrm{C}=60 \%$ ), with a $10 \%$ reciprocal value difference as above, is 1.17 (i.e., the genome of $\mathrm{D}$ is $17 \%$ larger than C). Similarly, a relative genome size difference ( $\mathrm{F}>\mathrm{E}$ by $33 \%$ ) can be calculated from data, indicating that $\mathrm{E} / \mathrm{F}=40 \%$ and $\mathrm{F} / \mathrm{E}=30 \%$.

Furthermore, as the difference in reciprocal reaction values increases, so does the magnitude of the difference in genome size.

In short, what we have said is that reciprocal value differences among highly related strains are indicative of smaller genome size differences than the same reciprocal value differences among less highly related strains. Also, as the reciprocal value differences increase, so do the relative genome size differences, and also conversely.

Using this argument, we can calculate (again, assuming the reciprocal difference values to be significant) that the genome size of $V$. psychroerythrus NCR 1004 is eight times larger than that of Vibrio sp. $5144 ; V$. parahaemolyticus A55 is $37 \%$ larger than that of $V$. costicolus NCMB $701 ; V$. anguillarum 30 is $36 \%$ larger than that of $V$. anguillarum $\mathrm{V}-2911$; and $V$. alginolyticus V-374 is $113 \%$ larger than that of $V$. parahaemolyticus ATCC 17802. Almost certainly, the first estimate is incorrect due to severe errors involved in determinations at that level, whereas the second and third estimates seem reasonable. The last estimate, although seemingly reasonable, is most probably incorrect because of the unusually low reciprocal value of $33 \%$ obtained for the $V$. alginolyticus V-374/V. parahaemolyticus ATCC 17802 reaction. Since Anderson and Ordal (1) have shown nearly identical reciprocal values for their $V$. 


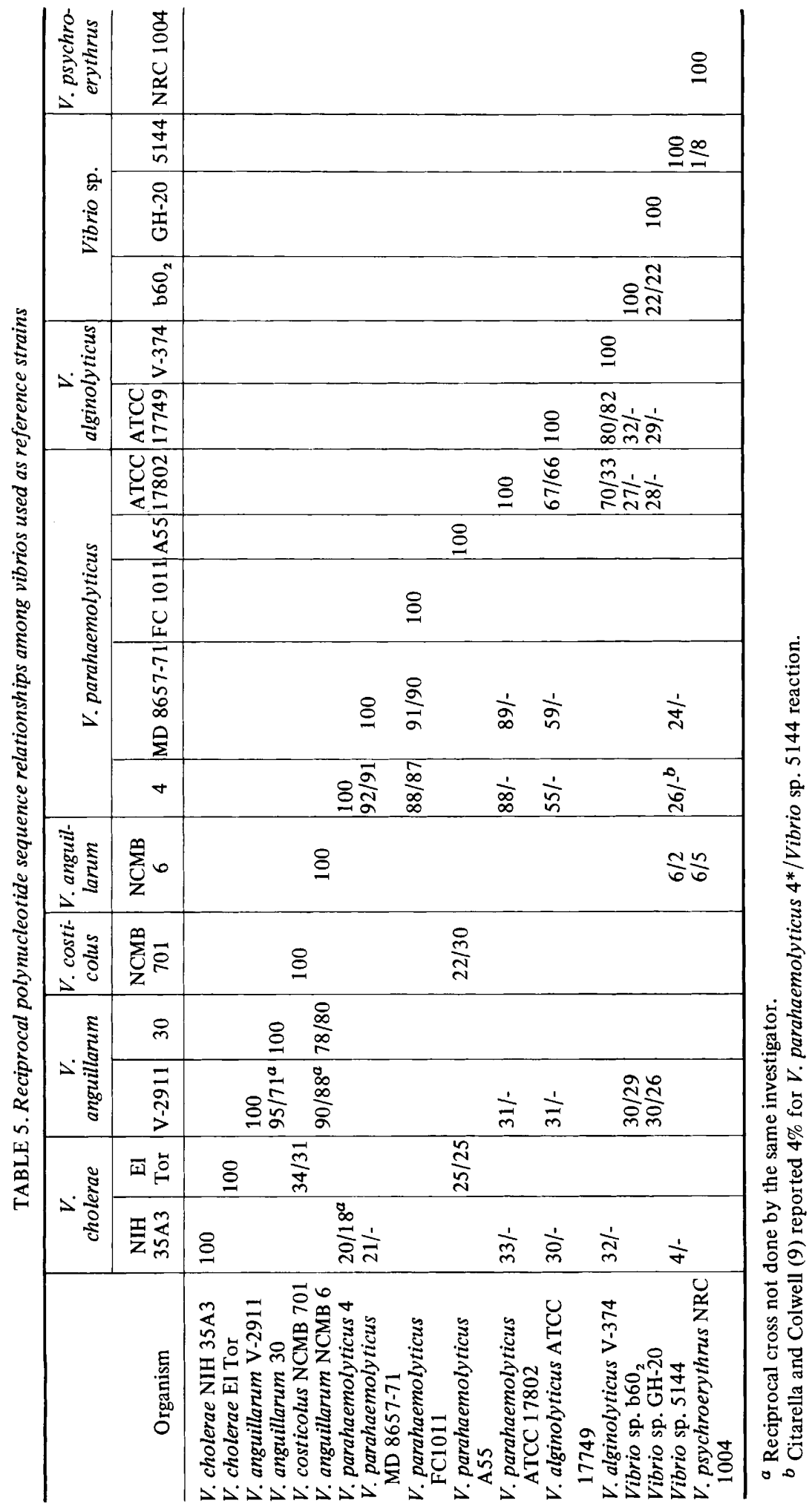


parahaemolyticus ATCC $17802 / V$. alginolyticus ATCC 17749 and $V$. alginolyticus ATCC $17749 / \mathrm{V}$. alginolyticus V-374 reactions, it necessarily follows that the $V$. alginolyticus $\mathrm{V}-374 / V$. parahaemolyticus ATCC 17802 reaction cannot be $33 \%$, but rather near $70 \%$.

In general, the majority of the reciprocal reactions performed to date have indicated relatively small (usually less than 10 to $15 \%$ ) differences in genome content among members of the genus Vibrio examined, especially among those strains exhibiting relatedness values of 20 to $25 \%$ or more.

Needless to say, many of the reciprocal reactions that are missing in Table 5 must be performed before we can conscientiously say that differences in genome content, regardless of the nature of the source, cannot severely influence interpretation of DNA reassociation data derived from studies with vibrios.

Furthermore, although one would prefer to use every strain as a reference strain, the relatively few data in Table 5 as yet do not indicate significant changes in the taxonomic groupings derived from Fig. 1 and compiled in Table 2. Obviously, a complete matrix of the data in Fig. 1 would be beneficial in more clearly defining taxonomic groupings and sorting out strains that now appear to cluster with a group merely on their common relationship to members of the groups. However, it may well be that the judicious selection of several reference strains (4 to 6 , perhaps) from each species cluster, compared with as many of the Vibrio strains as possible, might accomplish the same purpose. In addition, much more work has to be done with nonpathogenic vibrios before any valid molecular genetic limits of relatedness, with themselves or with other species, can be assigned.

Correlation of DNA reassociation data and mol percent guanine plus cytosine. The nucleotide base composition (mol percent guanine plus cytosine $[\mathrm{mol} \% \mathrm{G}+\mathrm{C}]$ ) of bacteria has been used in the past as a criterion for classifying organisms. The advent of DNA reassociation has, by and large, superceded this technique because the $\mathrm{G}+\mathrm{C}$ content of a particular DNA preparation tells nothing of the crucial arrangement of bases in sequence. Hence, the existence of organisms with identical $\mathrm{G}+\mathrm{C}$ content but very little phenetic or molecular genetic relationship with each other can be shown. As DeLey (12) has pointed out, the chance of two organisms being closely related decreases as the difference between their mean nucleotide composition increases, and, in fact, the chance nearly reaches zero when the mean nucleotide compositions differ by at least 18 to $30 \%$. Since the $\mathrm{G}+\mathrm{C}$ content of most of the species presently in the genus Vibrio ranges from 39 to $49 \%$ (9), the likelihood that some DNA relatedness exists among some of these species is, thus, reasonably high, although the DNA relatedness between organisms at each end of the $\mathrm{G}+\mathrm{C}$ range would predictably be very low.

Since the organisms listed in Table 1 are arranged according to polynucleotide sequence relationship, any correlation with nucleotide composition should be apparent. V. cholerae (including "classical" and El Tor vibrios) possess an overall $\mathrm{G}+\mathrm{C}$ content of $48 \% ; V$. anguillarum, 44 to $46 \%$ (one exception was $V$. anguillarum V-2911, which was $41 \%$ ); $V$. parahaemolyticus, 44 to $47 \%$; V. alginolyticus, 45 to $47 \%$; marine fish pathogens, 41 to $45 \%$; and the miscellaneous marine vibrios, 39 to $59 \%$.

These results, in general, agree well with those published by Bianchi (4) using organisms classified by numerical taxonomy procedures. The vast range of values for the miscellaneous marine vibrios, spanning $20 \% \mathrm{G}+\mathrm{C}$, reaffirms the heterogeneity of this group as determined by DNA reassociation and numerical taxonomy procedures. However, a range of approximately $10 \% \mathrm{G}+\mathrm{C}$ has been shown for the genera Pseudomonas, Mycobacterium, and Flexibacter.

\section{DISCUSSION}

Deoxyribonucleic acid hybridization studies among members of the genus Vibrio have been useful in classifying and identifying isolates thought to be identical by other criteria. However, the application of this technique in the development of a taxonomy for the genus has not been an outstanding success for several reasons. Firstly, only species pathogenic for man or animals have received significant attention, and, most assuredly, these represent only a few of the species of the genus as it is now defined. Secondly, the usefulness of the results of these studies (aside from corroborative evidence obtained from other classification methods) have been severely limited by the fact that arbitrarily selected strains have been employed as the reference strains. Thirdly, reciprocal reactions have not always been carried out. Furthermore, until recently, the consideration of mispaired base sequences in yielding unduly high \% DNA reassociation values, particularly in reactions involving more distantly related strains, has been neglected. In addition, with the exception of the notew orthy 
study of Anderson and Ordal (1), no generalized attempt has been made to compare several strains from a number of species within the genus. It is hoped that the obvious gaps, as evident in the data provided in Fig. 1, will be filled in the future. The delineation of species within the very heterogenous group of organisms presently lumped together as miscellaneous marine vibrios may then be accomplished.

In conclusion, the following generalizations can be made. (i) V. cholerae, $V$. anguillarum, and $V$. parahaemolyticus show intraspecies polynucleotide sequence variation from 80 to $100 \%$ and interspecies relatedness of approximately 20 to $30 \%$. $V$. parahaemolyticus shows relatively high (60 to $70 \%$ ) levels of relatedness to $V$. alginolyticus. It is not possible, at the present time, to place great reliance on other strain or species relatedness for the vibrios. (ii) Very little or no polynucleotide sequence relationship has been demonstrated between members of the genus Vibrio and members of the genera Pseudomonas, Aeromonas, Zymomonas, Cytophaga, or Escherichia. (iii) Based on the results of the majority of the reciprocal reactions presented, there appears to be no significant influence of genome size on DNA reassociation determinations within the genus Vibrio.

We reserve the right to make a dignified retreat from any one or all of the above mentioned conclusions as more DNA reassociation data accumulate for members of the genus Vibrio.

\section{REPRINT REQUESTS}

Address requests for reprints to: Dr. T. E. Staley, Department of Microbiology, University of Maryland, College Park, Md. 20742.

\section{LITERATURE CITED}

1. Anderson, R. S., and E. J. Ordal. 1972. Deoxyribonucleic acid relationships among marine vibrios. J. Bacteriol. 109:696-706.

2. Basden II, E. H., M. E. Tourtellotte, W. N. Plastridge, and J. S. Tucker. 1968. Genetic relationship among bacteria classified as vibrios. J. Bacteriol. 95:439-443.

3. Bauman, P., L. Bauman, and M. Mandel. 1971. Taxonomy of marine bacteria: the genus Beneckea. J. Bacteriol. 107:268-294.

4. Bianchi, M. A. G. 1973. Compositional en bases de L'ADN et position taxonomique de bactéries marines fermentant le glucose, du genre Vibrio et des genres voisins. Arch. Mikrobiol. 90:131-140.
5. Boling, M. E. 1972. Homology between the deoxyribonucleic acids of Haemophilus influenzae and Haemophilus parainfluenzae. J. Bacteriol. 112:745-750.

6. Brenner, D. J., G. R. Fanning, A. Rake, and K. E. Johnson. 1969. A batch procedure for thermal elution of DNA from hydroxyapatite. Anal. Biochem. 28:447-458.

7. Brenner, D. J., G. F. Fanning, F. J. Skerman, and S. Falkow. 1972. Polynucleotide sequence divergence among strains of Escherichia coli and closely related organisms. J. Bacteriol. 109:953-965.

8. Brenner, D. J., G. R. Fanning, K. E. Johnson, R. V. Citarella, and S. Falkow. 1969. Polynucleotide sequence relationships among members of the Enterobacteriaceae. J. Bacteriol. 98:637-650.

9. Citarella, R. V., and R. R. Colwell. 1970. Polyphasic taxonomy of the genus Vibrio: polynucleotide sequence relationships among selected Vibrio species. J. Bacteriol. 104:434-442.

10. Colwell, R. R. 1970 . Polyphasic taxonomy of the genus Vibrio: numerical taxonomy of Vibrio cholerae, Vibrio parahaemolyticus and related Vibrio species. J. Bacteriol. 104:410-433.

11. D'Aoust, J. Y., and D. J. Kushner. 1972. Vibrio psychroerythrus sp. n.: classification of the psychrophilic marine bacterium, NRC 1004.

12. Deley, J. 1969. Compositional nucleotide distribution and theoretical prediction of homology in bacterial DNA. J. Theoret. Biol. 22:89-116.

13. DeLey, J., and R. Tijtgat. 1970. Evaluation of membrane filter methods for DNA/DNA hybridization. Antonie van Leeuwenhoek J. Microbiol. Serol. 36:461-474.

14. Fukino, T., Y. Okuno, D. Nakada, A. Aoyama, F. Fukai, K. Murai, and T. Ueho. 1953. On the bacteriological examination of "shirasu" food poisoning. Med. J. Osaka Univ. 4:299-304.

15. Hanaoka, M., Y. Kato, and T. Amano. 1969. Complementary examination of DNA's among vibrio species. Biken J. 12:181-185.

16. Hendrie, M. S., W. Hodgkiss, and J. M. Shewan. 1971. Proposal that the species Vibrio anguillarum Bergman 1909, Vibrio piscium David 1972, and Vibrio ichthyodermis (Wells and ZoBell) Shewan, Hobbs, and Hodgkiss 1966 be combined as a single species, Vibrio anguillarum. Int. J. Syst. Bacteriol. 21:64-68.

17. Johnson, J. L., R. S. Anderson, and E. J. Ordal. 1970. Nucleic acid homologies among oxidasenegative Moraxella species. J. Bacteriol. 101:568-573.

18. Kiehn, E. D., and R. E. Pacha. 1969. Characterization and relatedness of marine vibrios pathogenic to fish: deoxyribonucleic acid homology and base composition. J. Bacteriol. 100:1248-1255.

19. Liston, J., W. Wiebe, and R. R. Colwell. 1963. Quantitative approach to the study of bacterial species. J. Bacteriol. 85:1061-1070.

20. Pacha, R. E., and E. D. Kiehn. 1969. Characterization and relatedness of marine vibrios pathogenic to fish: physiology, serology and epidemiology. $J$. Bacteriol. 100:1242-1247. 
21. Palleroni, N. J., R. W. Ballard, E. Ralston, and M. Douderoff. 1972. Deoxyribonucleic acid homologies among some Pseudomonas species. J. Bacteriol. 110:1-11.

22. Sakazaki, R. 1968. Proposal of Vibrio alginolyticus for the biotype of $V$. parahaemolyticus. Jap. J. Med. Sci. Biol. 21:359-362.

23. Seidler, R. J., and M. Mandel. 1971. Quantitative aspects of DNA reassociation: base composition, state of chromosome replication and polynucleotide homologies. J. Bacteriol. 106:608-614.

24. Shewan, J. M., G. Hobbs, and W. Hodgkiss. 1960. A determinative scheme for the identification of certain Gram-negative bacteria, with special refer- ence to the Pseudomonadaceae. J. Appl. Bacteriol. 23:379-390.

25. Smith, F. B. 1938. An investigation of a taint in rib bones of bacon. The determination of halophilic vibrio (N. spp.) Proc. Roy. Soc. Queensland 49:29-52.

26. Smith, I. W. 1961. A disease of finnock due to Vibrio anguillarum. J. Gen. Microbiol. 24:247-252.

27. Staley, T. E., and R. R. Colwell. 1973. Polynucleotide sequence relationships among Japanese and American strains of Vibrio parahaemolyticus. J. Bacteriol. 104:916-927. 